\title{
Business Model Innovation of Bicycle Sharing From Perspective of Sustainable Economic Development
}

\author{
Yunqi Wang ${ }^{1, *}$, Liang $\mathrm{Li}^{2}$ and Daiqingwen Luo ${ }^{1}$ \\ ${ }^{1}$ International Business Faculty, Beijing Normal University, Zhuhai, 519087 \\ ${ }^{2}$ Shandong University of Technology, Shandong, 255049 \\ *Corresponding author. Email: yunqiwang@sina.com
}

\begin{abstract}
As the typical representative of sharing economy, bicycle sharing is not only the result of technological innovation, but also the innovation of product designing and business model. From the massive influx of bicycle sharing brands into the market in 2016 to the subsequent rapid withdrawal, and then to the following collective price increase adjustment, the sustainable development of bicycle sharing as business model innovation has become a topic of concern of all sectors.

This paper analyses the business model innovation of bicycle sharing from perspective of sustainable economic development. With clear target customers and huge market potential, when bicycle sharing suppliers could provide consumers with better experience than those given by their competitors, their market share would be secured and expanded, and sustainable economic development could then be achieved.
\end{abstract}

Keywords: Sharing economy, Bicycle sharing, Business model innovation, Sustainable development.

\section{INTRODUCTION}

Beginning in the latter half of 2016, bicycle sharing has emerged as a new fashion for public transportation and quickly become a part of people's daily lives. Apart from the early brands like Mobike and oFo, at least 25 new bicycle sharing brands have entered the market throughout 2016. And by July 2017, there were nearly 70 brands across the country and more than 16 million bikes were provided on the market. Bicycle sharing as business model innovation has then become a topic of concern of all sectors.

It seems like a corresponding to the early massive and sudden influx of bicycle sharing brands, the market has then witnessed the subsequent rapid withdrawal. And by 2019 , no more than five bicycle sharing brands are still found left on the market and each announced a new pricing schemes. For this collective price increases, suppliers provided almost identical explanation which is to achieve sustainable development.

As the typical representative of sharing economy, bicycle sharing is not only the result of technological innovation or a new product designing idea, but also the innovation of business model. This paper analyses the business model innovation of bicycle sharing from perspective of sustainable economic development.

\section{BICYCLE SHARING AND SUSTAINABLE DEVELOPMENT}

In 1978 American sociology professor Marcus Felson and Joe L Spaeth proposed for the first time the concept of sharing economy in their paper Community Structure and Collaborative Consumption: A Routine Activity Approach. They believe that with the help of a market platform created by a third party such as a commercial institutions, organizations or government institutions, individuals could exchange their idle items, share knowledge and experience or even raise funds for enterprises or innovation projects. The concept of sharing economy has then appeared onto the market.

\subsection{Definition of Sharing Economy}

Even though scholars may provide explanation from different perspectives, they all believe that sharing economy is an arrangement that helps to realize fully utilization of resources with temporary paid transfer of the use rights. If resources are found idle, owners could choose to transfer the use rights of these resources to 
others and for a usage fee. When use right is separated from ownership, idle resources have more opportunities to be fully used and then value created.

According to China's Sharing Economy Development Report 2016 (hereinafter referred to as the Report) issued by China Electronic Commerce Research Center, the sharing economy market could be divided into seven major segments which include transportation sharing, catering sharing, logistics sharing and etc. Among which transportation sharing takes the top market share.

\subsection{Bicycle Sharing}

With the acceleration of industrialization and urbanization, China which once was the Bicycle Kingdom has also undergone tremendous changes in the choice of means of transportation. With the increasing development of urban public transportation systems and rapid popularity of private cars, daily commuting seems to be no longer a problem.

But the fact is far from perfect. Even though it could provide efficient, convenient, and low-cost terminal to terminal services, the highly advanced urban transportation system still cannot meet commuters' need for "door-to-door" services. The so called "last mile" that always exists between transportation terminals and commuters' final destination is a realistic problem that the public transportation system can hardly solve. And the larger the city, the more so the case. The gap between the service coverage that public transportation network could provide and the need for customized commuting routes has given rise to the demand for short-distance means of transportation.

As a business model innovation, since its launch onto the market, bicycle sharing has positioned its services as to provide commuters with an easy to operate and on-demand means of transportation so as to meet their need for short-distance travel. By simply scanning the QR code to unlock bicycles and paying low usage fee, commuters could easily ride to any destinations and do not need to worry about parking. By perfectly bridging the gap between public transportation terminals and commuters' final destination and holding its born with environment friendly attributes, bicycle sharing has gained huge number of customers immediately upon its launch onto the market. And a lot of new brands then appear on the market. By July 2017, there were nearly 70 bicycle sharing brands on the market with more than 16 million bicycles being provided.

But the rapid influx of bicycle sharing brands in the initial period is followed by a subsequent rapid withdrawal. And by 2019 no more than five brands left on the market. The dramatic changes in the number of brands have given rise to the discussion of sustainable development of bicycle sharing as business model innovation.

\subsection{Sustainable Development}

According to the definition given by United Nations, sustainable development refers to development that meets the needs of the present without compromising the ability of future generations to meet their own needs. Sustainable development has of three pillars: economy, society and environment, which are interrelated and mutually reinforcing. Whatever business model is chosen, sustainable development could only be achieved when all three pillars have been taken into consideration. Focusing on economic pillar, the paper analyses the business model innovation of bicycle sharing from perspective of sustainable economic development.

Sustainable economic development, or economic pillar, deals with the real existence of business enterprises, which is to maximize shareholders' value and thus related to the profitability of enterprises. Only when enterprises achieve sustained profit could they secure the opportunity to stay on the market and provide better services. And when it comes to bicycle sharing, for the collective price increases since March 2019, suppliers provide almost identical explanation which is to achieve sustainable development. To stay and grow on the market, enterprises need to maintain financial sustainability and proper price adjustments provide a possible solution.

\section{BUSINESS MODEL}

From economic perspective, whatever business model is chosen, the decision-making process involves three important issues: what to produce, how much to produce and for whom to produce. Since the market share of, or quantity of products could be sold out by each supplier is determined by market potential and the number of competitors, bicycle sharing as a business model need to answer the following three core questions: (1) who are the customers; (2) whether the market potential is large enough; and (3) who are/ will be the competitors.

\subsection{Who Are the Customers}

Whatever business model is chosen, this is always the first question need to be answered. Enterprises need to focus on a clear group of target customers or target market.

Not surprisingly, social sciences (both economics and management) have put equal emphasis on this topic. "For whom to produce" is the first among all three major economic decisions while "managing the valuable customer relationship" is exactly the core idea of 
marketing. Only when enterprises clearly know their target customers and fully understand their needs can they build and maintain long-term customer relationships by providing exactly the products that meet consumer preferences and ultimately achieve on-going profitability and sustainable economic development.

Ever since its initial launching, bicycle sharing has positioned its target market clearly which is to provide short-distance transportation services. By providing commuters with an easy to operate and on-demand means of transportation to bridge the gap between public transportation terminals and commuters' final destination, bicycle sharing is here to deal with the so called "last mile" anxiety. In short, the target customers of bicycle sharing are those daily commuters and students with rigid short-distance transportation demand.

Data from different research institutions, gathered in different sample cities and based on different statistical indicators show that bicycle sharing services are used most frequently between 7: 30 - 9: 30 am and 17: 30 19: $30 \mathrm{pm}$, which just coincides with peak traffic hours. And the riding distance falls mainly within 5,000 meters with $64 \%$ customers riding within $1 \mathrm{~km}$ and $86 \%$ within $2 \mathrm{~km}$ (including $2 \mathrm{~km}$ ). When it comes to the time duration of any single riding, a majority of $76 \%$ customers use the services for less than 15 minutes. Actually data give a clear picture of three characteristics of bicycle sharing customers which are relatively fixed usage time, short usage time duration and short riding distance. This is in line with the market positioning of bicycle sharing which is to serve customers with rigid short-distance transportation demand. All the above evidences show that bicycle sharing has a clear target market and has met its customers' needs well.

\subsection{Is the Market Potential Large Enough}

Market potential is always a most important concern of enterprises and the logic behind is simple. Only large market potential could support large output which thereby generates high revenues and then profits. If taking scale economies into consideration, cost could also be further reduced when there is large market potential and profits then increased accordingly. And this is especially true for industries that require relatively high fixed inputs. From economic perspective, large market potential is an important guarantee to generate scale economies, reduce costs, increase profits and finally achieve sustainable economic development.

According to China Bicycle Sharing Market Research Report 2016 released by BDR (Big Data Research), a third-party data research institution, by the end of 2016, the total number of users of bicycle sharing has reached 18.86 million. And another data from China
Ministry of Transport shows that in 2018 the usage of bicycle sharing was still more than 10 million times per day across the country. Solid evidence supports the idea that bicycle sharing does have large market potential. When combining the fact that most customers of bicycle sharing are those daily commuters and students with rigid short-distance transportation demand, the market potential is obviously huge.

From economic perspective, enterprises are all rational and their decisions are thus results of rational judgement. Following this logic, the shared bicycles everywhere across cities provide testimony to the above description of the market potential. Because only when market potential is large enough would suppliers have the intention to provide the huge amount of bicycles.

\subsection{Who Are the Competitors}

While market potential is the maximum or boundary that an industry could ever grow, market share that each supplier could acquire will be determined by competitors on the market.

Since consumers are always rational and consumption are always exclusive, rational consumers will always choose the "best" among all available choices. Suppliers that have not been chosen will lose market share in the competition. To this end, suppliers have to try every possible ways not only to attract consumers but also to retain them which is obviously more important. Especially when both the number of suppliers and market potential are relatively stable, whether a supplier could provide better user experience become the key determinant when allocating market shares.

Suppliers are thus required to keep an eye on their competitors at all times, not only existing competitors already in the market, but also potential coming ones that might enter in the near future. Suppliers need to observe and analyse competitors' various efforts and attempts in providing better customers' experience and take it as references to improve their own products. Also at the same time, to understand better consumers' requirements and preferences and build a strong customer relationship by continuously improving their experience so as to stabilize and expand market share and achieve sustainable economic development.

\section{CONCLUSION}

As the typical representative of sharing economy, bicycle sharing is not only the result of technological innovation or a new product design idea, but also the innovation of business models. From the massive influx of bicycle sharing brands in 2016 to no more than five brands still left in the market in 2019, and then to the following collective price increases, sustainable 
development has become the big problem faced by this business model innovation.

This paper analyses the business model innovation of bicycle sharing from perspective of sustainable economic development and find,

(1) Bicycle sharing aims to provide services to consumers with short-distance transportation needs. This market positioning is in line with the needs of target customers and therefore meets the expectation of target customers well.

(2) The market potential of bicycle sharing is large enough to support a high output level. Considering the further cost reductions from scale economy, suppliers could achieve sustainable profits and then financial sustainability.

(3) Since consumers are rational and consumption are exclusive, only those suppliers that could provide consumers with better experience than those given by their competitors could retain consumers, stabilize and expand market share, and achieve financial sustainability. To do this, suppliers need to keep an eye on their competitors.

\section{REFERENCES}

[1] Mobike Trip Report 2018 [O/L], http://www.hbspcar.com/2403.html, 2019-12-22.

[2] China Bicycle Sharing Market Research Report $[\mathrm{O} / \mathrm{L}]$, http://www.hbspcar.com/1684.html, 2019-12-22.

[3] Bigdata Research, http://www.bigdata-research.cn/.

[4] Bicycle sharing usage in China. Ministry of Communications $[\mathrm{O} / \mathrm{L}]$, http://finance.people.com.cn/n1/2018/1221/c100430481237.html, 2019-12-22. 